\title{
Study on Hysteretic Fracture of Naturally Cracked Surrounding Rock
}

\author{
Zhibin Zhong, ${ }^{1}$ Ronggui Deng, ${ }^{1}$ Fang Lin, ${ }^{1}$ Ying Zhang, ${ }^{1}$ Lei Lv, ${ }^{2}$ \\ Jing Yin, ${ }^{1}$ and Xiaomin $\mathrm{Fu}^{3}$ \\ ${ }^{1}$ School of Civil Engineering, Southwest Jiaotong University, Chengdu, Sichuan 610031, China \\ ${ }^{2}$ Chengdu Southwest Jiaoda Yaosen Engineering Technology Co., Ltd., Chengdu, Sichuan 610031, China \\ ${ }^{3}$ State Key Laboratory of Geohazard Prevention and Geoenvironment Protection, Chengdu University of Technology, \\ Chengdu, Sichuan 610059, China
}

Correspondence should be addressed to Ronggui Deng; drg60@163.com

Received 25 August 2015; Accepted 28 October 2015

Academic Editor: Salvatore Caddemi

Copyright (c) 2015 Zhibin Zhong et al. This is an open access article distributed under the Creative Commons Attribution License, which permits unrestricted use, distribution, and reproduction in any medium, provided the original work is properly cited.

\begin{abstract}
To determine the hysteretic fracture mechanism of the hard and naturally cracked surrounding rock mass, uniaxial and biaxial compression tests were performed on rhyolite specimens. In the biaxial compression test, displacements and strains around the U-shaped opening were monitored throughout to study the fracture pattern and distribution of stress. To compare with the experimental results, the finite difference code FLAC $^{3 \mathrm{D}}$ was used to simulate a perfectly intact rock model with the same geometric and mechanical conditions in a continuum model. Stress-strain curves under uniaxial compression and the surrounding rock stresses of numerical results were compared with laboratory test. On one hand, laboratory test and numerical results all showed that tensile fracture regions were found at the crown and floor of the opening while shear regions are found at the sidewall. On the other hand, due to microcracks in the laboratory specimen, the laboratory test showed lower ultimate compressive strength. However, its vertical displacement of initial fracture was larger than those of numerical model which did not consider about the microcracks. They revealed the hysteretic fracture behaviour of underground opening in hard and cracked rock.
\end{abstract}

\section{Introduction}

Niba mountain tunnel, located on the expressway between Beijing and Kunming in Sichuan province, is $11 \mathrm{~km}$ long with a maximum overburden of $1660 \mathrm{~m}$. Due to the complex geologic structure of the east Qinghai-Tibetan Plateau, the greatest challenge is the failure of cracked surrounding rock. During its excavation, rock burst often occurred behind the working face of the rock which is named hysteretic fracture.

Joints and cracks have great influence on the mechanical characteristics of rock. Extensive experimental studies have been conducted on rock or rock-like material specimens with preexisting regular artificial cracks. These studies have indicated that the fracture characteristics of preexisting cracks are closely related to the lithology, length, and distribution of cracks and the test loading path. The cracks lead to the coalescence and unstable failure of rock and rock-like materials [1-3]. Jia et al. [4] performed uniaxial compression test on brittle carbonate rock, and acoustic emission (AE) and CT imaging technology were used to investigate the interconnection of microcracks, forming macroscopic fracture failure. Eberhardt et al. [5] believed that cracks in rock could degenerate its strength and proposed detailed analysis of the crack initiation and propagation thresholds. Based on PMMA, molded gypsum and Hwangdeung granite containing preexisting cracks, Lee and Jeon [3] considered that different material and geometry of preexisting cracks held the different crack initiation, propagation, and coalescence.

Furthermore, some studies have focused on the fracture characteristics of jointed surrounding rock with openings. These studies showed that the cracks propagate to macrocracks, which lead to failure of the surrounding rock. Ewy and Cook [6] observed the growth of small, opening-mode, splitting cracks oriented parallel to the tangential stresses, starting 
very close to the hole wall and occurring deeper in the rock with increasing stress. Fakhimi et al. [7] conducted a biaxial compression test on sandstone with a circular opening. Two notches were developed at the lateral boundaries of the hole due to the stress concentration and the failure planes were inclined to the axial direction. Based on the ubiquitous-joint model, Wang and Huang $[8,9]$ examined the distribution and mechanical properties of joints in intact rock and analyzed the failure characteristics of regularly heterogeneous cracked surrounding rock in theory. Using the dislocation model and strain energy density factor theory, Zhou et al. [10] analyzed the nucleation, growth, interaction, and coalescence of cracks. Moreover, numerical simulation methods have been employed to simulate the fracture of surrounding rock. Zhou et al. [11] studied the effect of cracks and joints on fracture of surrounding rock for the underground caverns of Jinping I hydropower station. Sagong et al. [12] investigated the rock fracture and joint sliding behaviour of persistent jointed rock masses with an opening under biaxial compression. Zhang et al. [13] studied the deformation and failure characteristics surrounding the deep caverns by model test and theoretical analysis methods. Souley et al. [14], Hao and Azzam [15], and Jiang et al. [16] described the fracture process of rock around a tunnel using discrete element modelling (DEM). Meanwhile, Zhu et al. [17] and Jia and Tang [18] examined the microscopic damage and heterogeneity of rock using the finite element modelling (FEM) software RFPA. Progressive fracturing processes around circular, elliptical, and U-shaped underground excavations were simulated.

In summary, many experimental and theoretical studies have been conducted to reveal the fracture characteristics of cracked and jointed rock [1-5]. Then, fracture and failure modes of surrounding rock in homogeneous and preexisting regular jointed rock with circular openings were also investigated $[6-12,19]$. Furthermore, numerical simulations have been performed to investigate the progressive fracturing process of different geometric opening and the effect of joint geometric parameters [14-18]. These studies have produced many substantial achievements and contributed to the study of the fracture mechanism of cracked underground surrounding rock. However, homogeneous surrounding was idealized model while cracks significantly affect the mechanical characteristics of rock. In addition, circular tunnel sections are rarely found in underground engineering projects. Above all, there was hardly any study forced on the difference between cracked and intact surrounding rock. Due to the numbers of hysteretic fractures observed during the excavation of Niba mountain deeply buried and long tunnel, it was necessary to reveal the mechanism of hysteretic fractures in cracked and hard surrounding rock.

In this paper, experimental and numerical simulation are conducted to evaluate the deformation and fracture modes of rock with an inverted $\mathrm{U}$-shaped opening in natural original cracked and noncracked rhyolite, respectively. In Section 2, experimental processes which include uniaxial and biaxial compression tests are described in detail. In Section 3, the fracture modes of uniaxial and biaxial compression specimens are analyzed; meanwhile, surrounding rock stresses around the opening are illustrated. In Section 4, numerical models with intact rock are established to compare with the experimental results in fracture modes and variations of surrounding rock stresses. Finally, conclusions are drawn in Section 5. The stress distribution, failure process, fracture mechanism, and characteristics are examined by biaxial compression loading to simulate the hysteretic fracture after excavation. Numerical results show the difference between cracked and intact surrounding rock regarding the stress field and fracture behaviour.

\section{Experimental Process}

2.1. Experimental Specimen Setup. The rhyolite used to manufacture the specimen was obtained from the Daxiangling Niba mountain tunnel on the expressway from Beijing to Kunming (G5) in Sichuan province. The tunnel is $10,017 \mathrm{~m}$ long with a maximum overburden of $1660 \mathrm{~m}$. Due to the complex geological structure, the rhyolite in the tunnel region is highly cracked. Rock burst, hysteretic fracture occurred frequently during excavating of the tunnel [20]. In this section, firstly uniaxial compression test was conducted to investigate the basic mechanical characteristic. The specimen used to perform uniaxial compression test was dug from the biaxial specimen (see Figure 1). Then biaxial compression test, whose specimen contained an inverted U-shaped opening, was carried out to investigate the fracture modes and distribution laws of stresses around the opening.

Based on the load capacity and dimensions of the loading apparatus, the dimensions of the biaxial specimen were $120 \mathrm{~mm} \times 120 \mathrm{~mm} \times 60 \mathrm{~mm}$. As it was difficult to perfectly cut a horseshoe-shaped opening in a hard and cracked rock specimen and considered about the boundary effect, simplified $20 \mathrm{~mm}$ straight-wall $40 \mathrm{~mm}$ top semicircular arch inverted U-shaped opening was manufactured in the middle. Li et al. [21] and Zhu et al. [17] used this kind of model to successfully analyze the mechanics and failure behaviour of tunnels.

2.2. Loading and Monitoring Conditions. All the tests were performed in the State Key Laboratory of Geohazard Prevention and Geoenvironment Protection of Chengdu University of Technology. The uniaxial compression tests were performed on the MTS815 Rock Mechanics Test System (Figure 2(a)). The maximum loading capacity of axial servocontrolled system is $3000 \mathrm{kN}$. During the uniaxial tests, the axial force and deformation were measured by a loading cell and LVDTs, respectively. The biaxial compression test was performed on the self-designed Rock Biaxial Compressive Test System (RBCTS) (Figure 2(b)), which was designed in and controlled by a computer program. The applied load and boundary displacement of the specimen data were automatically recorded at a rate of 10 samples per second. Loading was applied through horizontal and vertical hydraulic lifting jacks with maximum loads of $300 \mathrm{kN}$ and $600 \mathrm{kN}$, respectively, while the left and bottom restraint plates were fixed. Steel balls were installed at the left, upper, and bottom boundaries of the loading frame, and a restraint plate lubricated with butter with its surface facing the specimen was placed on the specimen to eliminate the boundary effects. The loading 


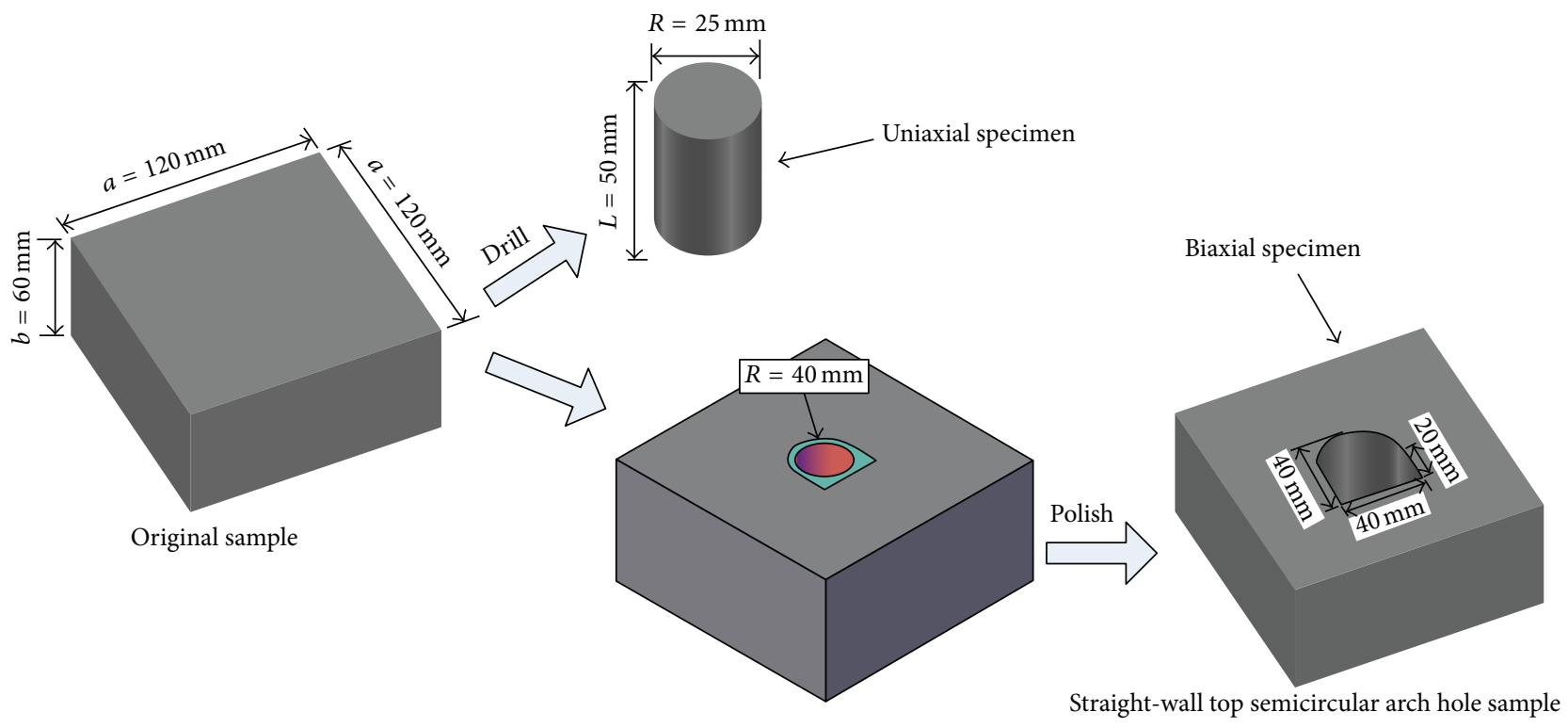

FIGURE 1: Manufacturing of specimens.

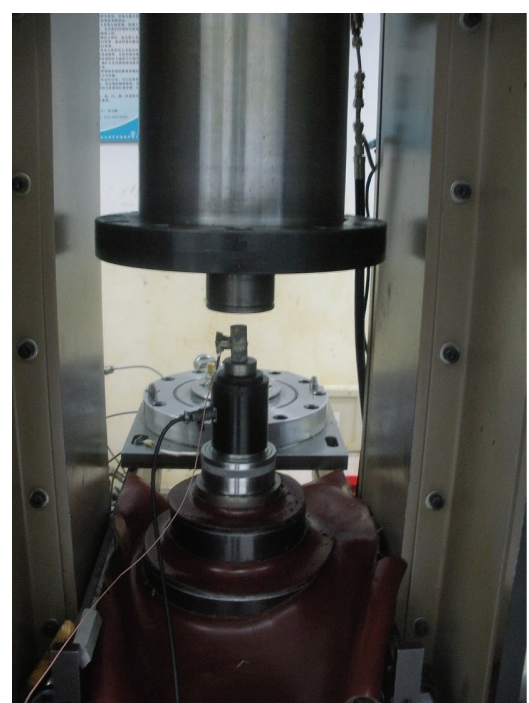

(a)

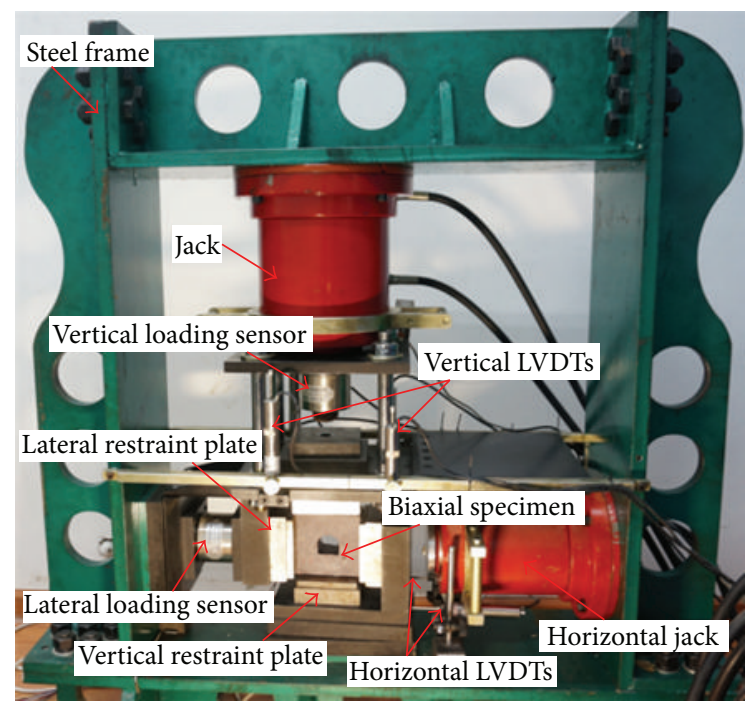

(b)

FIGURE 2: Experimental equipment and scheme: (a) MTS815, (b) RBCTS.

apparatus was constructed of high-duty steel, and reinforcement measures were implemented to satisfy the stiffness.

In addition, the loading rate of uniaxial compression was first controlled by axial force with a rate of $0.5 \mathrm{kN} / \mathrm{min}$ until the axial force arrived at $5 \mathrm{kN}$, and then the loading rate was transferred to axial deformation controlling with a loading rate of $0.1 \mathrm{~mm} / \mathrm{min}$ to obtain the postpeak deformation. To the biaxial compression test, the lifting-loading mode in this test consisted of the vertical pressure $\left(\sigma_{\mathrm{v}}\right)$ and horizontal pressure $\left(\sigma_{\mathrm{h}}\right)$ increasing simultaneously by $0.5 \mathrm{kN} / \mathrm{s}$ until a force of $7.2 \mathrm{kN}$ was reached, after which the horizontal pressure was kept constant $(7.2 \mathrm{kN})$ while the vertical pressure continued to increase until significant specimen failure was achieved. Finally, the horizontal and vertical pressures were removed to unload the specimen.

To monitor the fractures in the specimen, the indirect method, acoustic emission (AE) monitoring techniques, is used. The SAEU2S AE monitoring system contains AE event monitoring sensor and loading monitoring sensor. They can collect and display AE event emissions and the corresponding vertical loading timely (Figure 3(a)). The technique has been widely used to study the failure mechanism for rocks, concrete, and other materials. For biaxial compression test, based on the GMTS theory [22], the changes of tangential stresses around the opening were important for studying the fracture of rock during the test. Therefore, strain gauges were used 


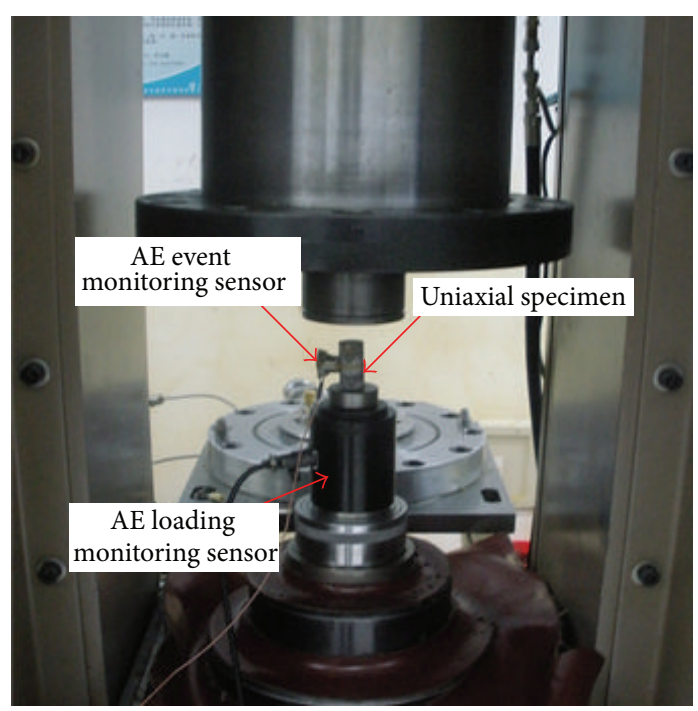

(a)

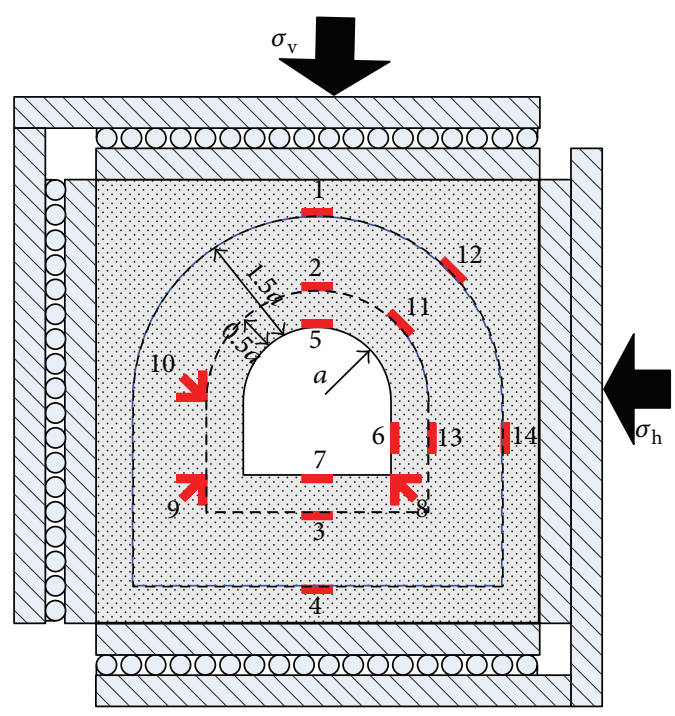

(b)

FIGURE 3: Experimental monitoring measures: (a) AE monitoring in uniaxial test, (b) strain gauges.

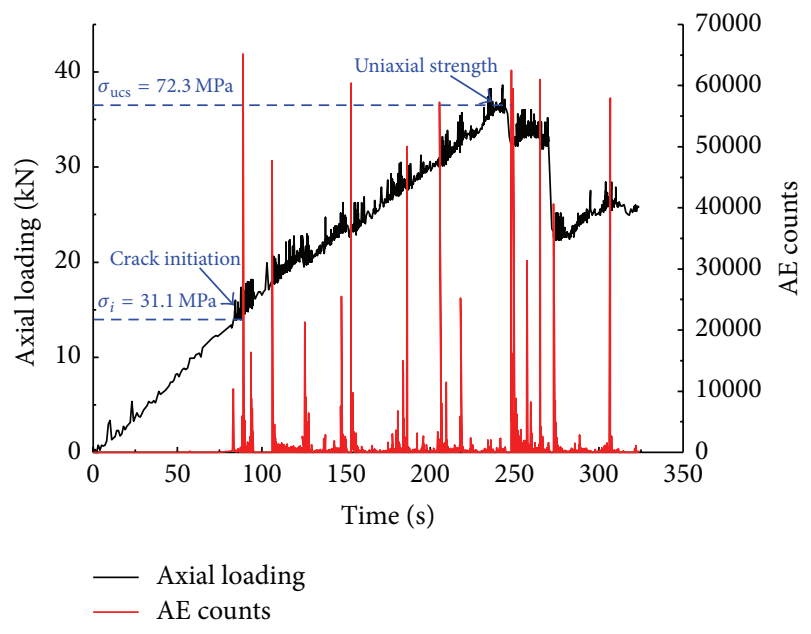

FIGURE 4: AE monitoring results of uniaxial compression test.

to measure the strains around and inside the opening. The distribution of the strain gauges was depicted in Figure 3(b). All the strain gauge, AE events, LVDT data, and loading records were transferred to and stored by computers. A digital camera was used to monitor and record the cracking process of the opening during the loading process.

\section{Experimental Results and Discussion}

3.1. Uniaxial Compression Test. Figure 4 showed the AE monitoring results during the test. It can be seen from Figure 4 that, in the elastic deformation stage, there was hardly any AE count measured, and the loading curve was relatively straight without remarkable fluctuations. Afterwards, AE counts suddenly increased and reached the highest when the axial stress was $31.1 \mathrm{MPa}$; it indicated that the microcracks in the specimen began to fracture; then $\sigma_{i}=31.1 \mathrm{MPa}$ was the crack initiation stress. For the uniaxial compression strength $\sigma_{\text {ucs }}=72.3 \mathrm{MPa}, \sigma_{i}$ was $43 \%$ of $\sigma_{\text {ucs }}$. Once the crack initiation stress reached, the AE counts increased continuously until the specimen fractured to failure. Additionally, sharply increased AE counts occurred when microcracks propagated to macrofracture with the external loading. As the stress reached the peak strength, a large number of AE events occurred abruptly, which indicated that isolated microfracture formed macrofracture plane in the rock specimen. In the postpeak stage, the AE counts were still high and more frequent, showing that microfractures continued to propagate and formed ultimate failure of specimen. They indicated that there were numbers of original microcracks in the specimen; once they reached the initiation stress, the cracks fractured and propagated continually with a mount of AE counts released.

Eberhardt et al. [5] developed the moving point regression technique to determine the stress thresholds of rock samples. It made use of a "sliding window" to scan through axial strain and axial stress data sets and superimposes a straight line over a user-defined regression interval. Using the method, Figure 5 showed the axial stress-strain curve and axial stiffness-strain curve. Based on the method, the axial stiffness curve was horizontal while the corresponding axial stress curve was oblique. Thus the slope of stress-strain curve was the elastic modulus in elastic deformation stage. Point A should be the crack initiation which was $39.0 \mathrm{MPa}$. It was larger than that observed by AE results. Comparing Figure 5 with Figure 4, AE monitoring results can investigate the fracture process more accurately.

Figure 6 showed the ultimate failure mode of the specimen. There was a distinct fracture plane approximately along the vertical which controlled the final failure of the specimen. It indicated that the rhyolite was brittle and splitting failure under uniaxial compression test. 


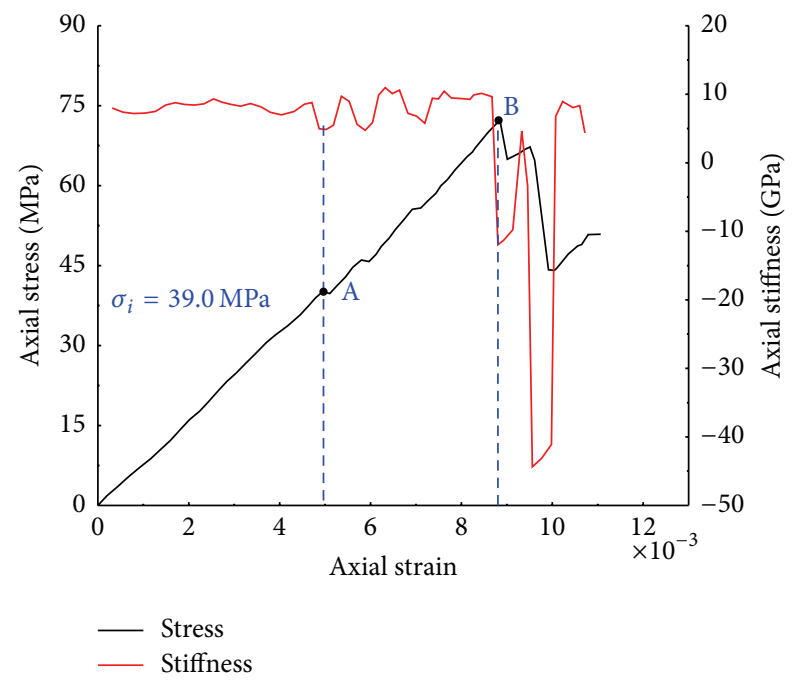

FIGURE 5: Experimental results of uniaxial compression test.

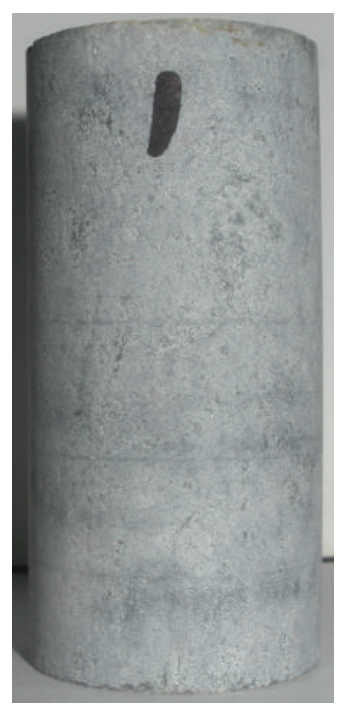

(a)

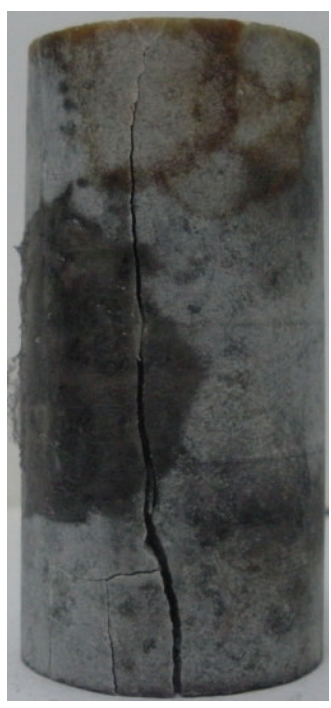

(b)
FIGURE 6: Ultimate failure mode of uniaxial compression test (a) before and (b) after the test.

\subsection{Biaxial Compression Test}

3.2.1. Fracture Characteristics and Processes of the Surrounding Rock. Figure 7 depicts the failure mode after the test. Three regions are distinguished according to the crack initiation sequence in the fractured area. With increasing vertical pressure, fractures were observed along regions (1), (2), and (3). Shear cracks initiate and propagate to macrofracture at arch spring. Further macrocrack planes shear off the sidewall and then slip into the opening. A large amount of rock detritus is observed in front of the shear opening, as shown on the left side of Figure 7. Meanwhile, a complete macrocrack plane is observed on the side of the specimen, as shown on the right side of Figure 7. It indicated that, during the test, the boundary effect is limited, and the cracks
TABLE 1: Fracture vertical displacements of surrounding rock.

\begin{tabular}{lccc}
\hline Location & $d_{\mathrm{v} 0 a} / \mathrm{mm}$ & $d_{\mathrm{v} 0.5 a} / \mathrm{mm}$ & $d_{\mathrm{v} 1.5 a} / \mathrm{mm}$ \\
\hline The crown & 1.13 & 1.26 & Unfractured \\
The floor & 0.81 & 0.93 & 2.27 \\
\hline
\end{tabular}

subperpendicular to the axial opening do not control the failure of specimen. The final failure of the specimen is controlled by the macrofractures in the loading plane.

In this test, the "V-shaped" compression-shear fractured region is formed at the sidewall near the arch springing point, and macro- and microscopic cracks are well developed. The shear and tensile cracks propagate towards the surrounding rock at the crown and floor, and then a shear wedge is observed at the crown and shears through the crushing area of the "V-shaped" notch, which results in more cracks at the reentrant and leads to its final fracture.

3.2.2. Stress Distribution Characteristics. According to above uniaxial and previous conventional triaxial compression tests $[20,23]$, the elastic modulus $E$ and Poisson's ratio $v$ of rhyolite are $8.7 \mathrm{GPa}$ and 0.1 , respectively. In biaxial compression tests, the normal strains in the tangential direction of the opening profile of the surrounding rock at crown and floor $\varepsilon_{n t}$ were monitored, as shown in Figure 3(b). The subscript "nt" means "normal value in the tangential direction of the opening profile." Then the normal stresses in the tangential direction of the opening profile, defined as $\sigma_{\mathrm{nt}}$, can be obtained based on Hooke's law, which is expressed as $\sigma_{\mathrm{nt}}=E \cdot \varepsilon_{\mathrm{nt}}$, and then their variations with vertical displacement, $d_{\mathrm{v}}$, can be plotted.

As shown in Figure 8, at either the crown or the floor, cracking begins with increasing tensile stress in the inner surface of the opening at $0 a$ from the opening profile. Next, $\sigma_{\mathrm{nt}}$ located at $0.5 a$ and $1.5 a$ from the opening profile orderly and gradually transform from compressive stress to tensile stress until the surrounding rock is tensile fractured. Meanwhile, strain energy is released to cause a sudden decrease in tensile stress. This indicates that the initiation, propagation, and coalescence of cracks can release the strain energy in the rock accumulated during the loading and then reduce the surrounding rock stresses. Table 1 summarises the vertical displacement values when the surrounding rock cracked at the crown and floor, where $d_{\mathrm{v} 0 a}, d_{\mathrm{v} 0.5 a}$, and $d_{\mathrm{v} 1.5 a}$ were the corresponding values of vertical displacements when the cracks were initiated at locations $0 a, 0.5 a$, and $1.5 a$ from the opening profile, respectively, and $d_{\mathrm{vf}}$ represented the final fracture vertical displacement.

In accordance with the variation of $\sigma_{\mathrm{nt}}$ at the crown and floor shown in Figure 8 and the corresponding vertical displacements, we can determine that the rock surrounding the floor fractures first and the cracks propagated to deeper locations markedly faster than those at the crown. Macrofractures occur once the cracks in the floor propagated to the boundary of the specimen, and the surrounding rock stresses were released. They indicated that the surrounding rock undergoes the stress adjustment processes of "bearing $\rightarrow$ initiation of cracks $\rightarrow$ stress release $\rightarrow$ bearing" during the test. Tensile and compressive stresses alternating occurred 


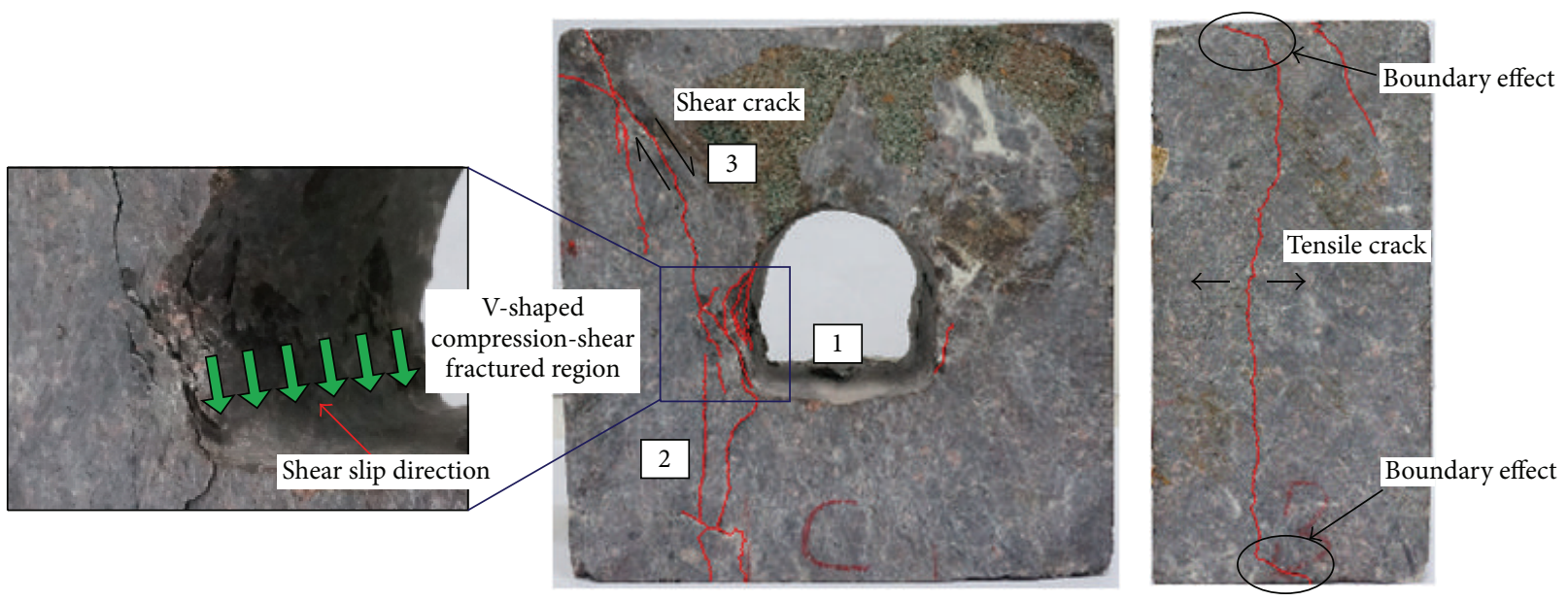

FIGURE 7: Final fracture mode of a biaxial specimen.

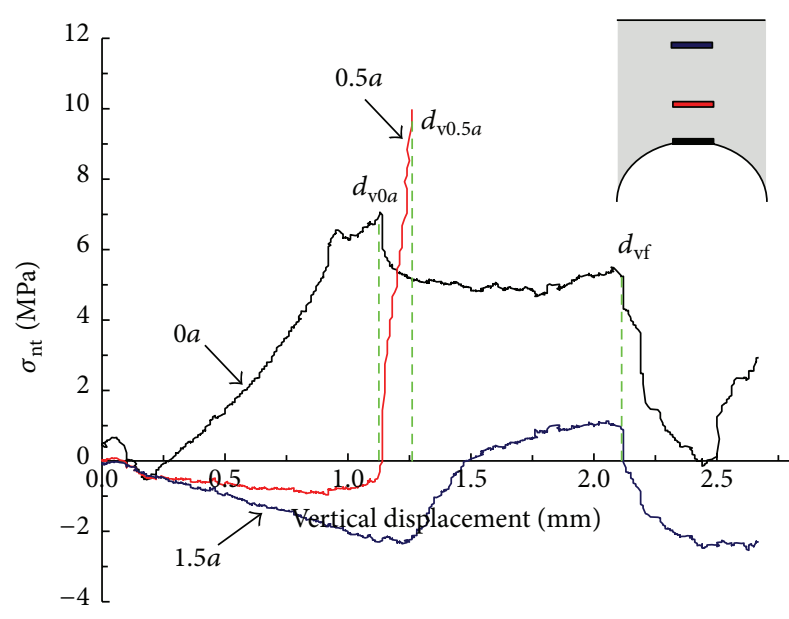

(a)

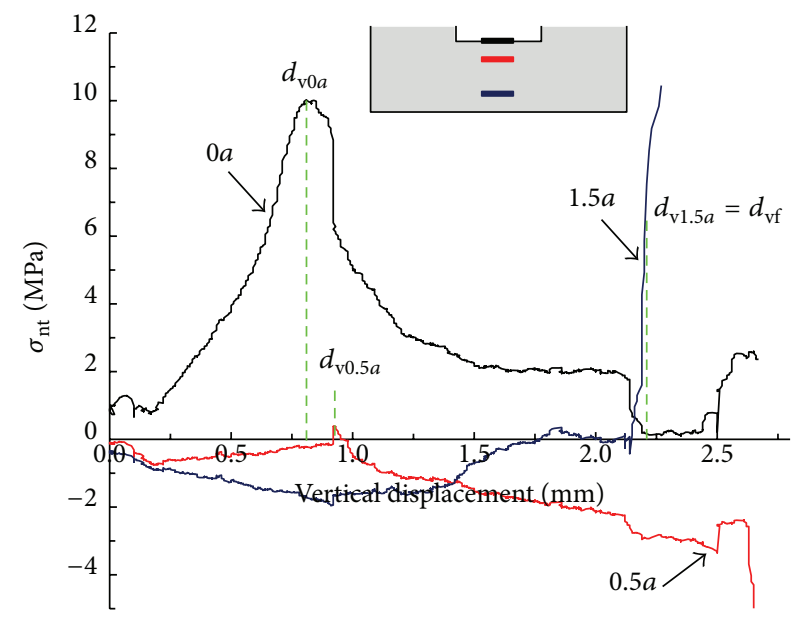

(b)

FIGURE 8: Variation of surrounding rock normal stresses in the tangential direction of the opening profile (a) at the crown and (b) at the floor.

in the surrounding rock, with the addition of new initiation cracks, which facilitated the cracking of the surrounding rock.

\section{Numerical Simulation Result and Discussion}

Joints, cracks, and other discontinuities in a rock mass play a key role in the responses of a tunnel. G. Barla and M. Barla [24] discussed and compared continuum and discontinuum modelling in tunnel engineering. The experimental results confirmed that the stress and fracture behaviour of naturally cracked surrounding rock are significantly affected by the yet-unknown distribution of cracks. Meanwhile, almost all natural rock contains different geometrical cracks. Therefore, it is difficult to prepare perfectly intact rock specimens to compare with cracked rock specimens under the same loading conditions in laboratory tests. On the contrary, numerical model can provide the perfectly intact rock specimen by continuum medium model [24]. To conduct the comparison, the finite difference code FLAC $^{3 \mathrm{D}}$ was used to simulate a perfectly intact rock model with the same geometric and mechanical conditions in a continuum model.

4.1. Simulation of Uniaxial Compression Test. Using a numerical model, a strain-softening model was selected to simulate the intact rhyolite (Figure 9). This method has been extensively used to describe the nonlinear mechanical properties of rock around a tunnel [25]. The equivalent physical properties of the simulated material referenced to the experimental results $[20,23,26]$ are shown in Table 2. To simulate the quasibrittle characteristics of rhyolite, the residual cohesive strength, residual internal friction angle, and residual tensile strength were achieved with an equivalent plastic shear strain of $1.0 \times 10^{-3}$. Because the rock specimen was intact, cracks were not considered. 
TABle 2: Physical properties of the numerical model material.

\begin{tabular}{|c|c|c|c|c|c|}
\hline & Elastic modulus/GPa & Poisson's ratio & Tensile strength/MPa & $c / \mathrm{MPa}$ & $\varphi /^{\circ}$ \\
\hline Initial value & 8.7 & 0.1 & 7.0 & 15.0 & 50 \\
\hline Residual value & 8.7 & 0.1 & 0.01 & 13.0 & 40 \\
\hline
\end{tabular}

TABLE 3: Comparison of the fractured vertical displacements units: $\mathrm{mm}$.

\begin{tabular}{|c|c|c|c|c|c|c|}
\hline Location & Result & $d_{\mathrm{v} 0 a}$ & $\Delta d_{\mathrm{v} 0 a}$ & $d_{\mathrm{v} 0.5 a}$ & $\Delta d_{\mathrm{v} 0.5 a}$ & $d_{\mathrm{vl} .5 a}$ \\
\hline \multirow{2}{*}{ The crown } & Numerical & 0.22 & \multirow{2}{*}{0.91} & 0.80 & \multirow{2}{*}{0.46} & Unfractured \\
\hline & Experimental & 1.13 & & 1.26 & & Unfractured \\
\hline \multirow{2}{*}{ The floor } & Numerical & 0.18 & \multirow{2}{*}{0.63} & 0.34 & \multirow{2}{*}{0.69} & Unfractured \\
\hline & Experimental & 0.81 & & 0.93 & & 2.27 \\
\hline
\end{tabular}

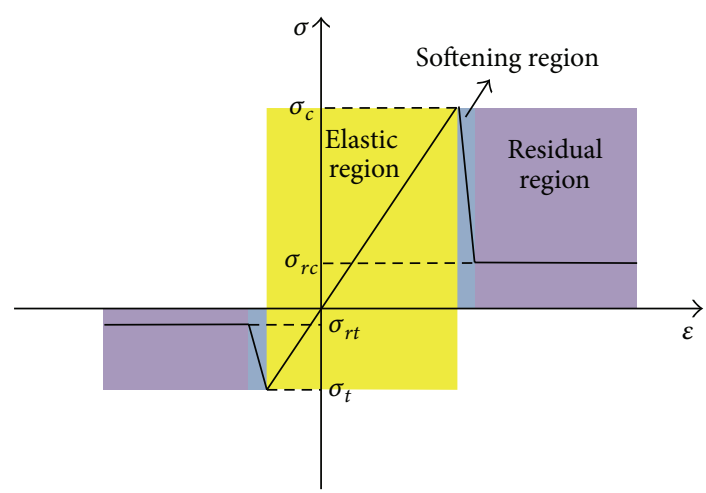

FIGURE 9: The strain-softening model.

The uniaxial compression numerical model was the same size as the experimental model and was divided into a total of 20000 eight-noded hexahedron elements. The upper and bottom boundaries were both constrained, and then vertical compressive displacement was applied in the upper boundary at a rate of $1.0 \times 10^{-8} \mathrm{~m}$ per step for the total steps of 60000 . Then the axial stress-strain curve of the numerical result was compared with the test result which was mentioned in Section 3.1. As shown in Figure 10, the numerical result showed a good agreement with the laboratory test results. It indicated that the parameters used in the numerical model were acceptable. Therefore, they could be used to simulate the biaxial compression test.

4.2. Simulation of Biaxial Compression Test. Figure 11 showed the typical mesh pattern generated when simulating perfectly intact surrounding rock. In FLAC ${ }^{3 \mathrm{D}}$, concentrated loads were specified at given surface nodes, and imposed boundary displacements were prescribed in terms of nodal velocities [27]. In this numerical model, the frontage and backside of the numerical model were both free boundaries, while the displacements along the $x, y$, and $z$ directions of the upper and bottom boundaries were both constrained. Otherwise, the left and right sides were only constrained by the displacement of the $x$ direction with the application of 1.0 MPa of lateral pressure, which was maintained during the calculation. Vertical compressive displacement was applied at a rate of $2 \times 10^{-8} \mathrm{~m}$ per step. For the simulation, the step size was set as 130,000 , and the total vertical displacement was $2.6 \mathrm{~mm}$. The numerical model was the same size as the experimental model and was divided into a total of 32,640 eight-noded hexahedron elements. When the model was solved, to define velocity variations and corresponding space intervals, the medium was discretized into constant tetrahedral strain-rate elements with vertices represented by the nodes of the mesh [27].

Figures 12 and 13 showed the principal stresses and plastic region of numerical simulation results. It can be seen that the crown and floor of the opening were subject to tension stress which controlled the tensile fracture of the locations. On the contrary, the region of sidewall was subject to principal compressive stress and led to shear fracture in this region. In addition, an oblique shear fracture plane was observed near the arch spring line. The fracture behaviour of numerical simulation results showed good agreement with the experimental results.

Figure 14 depicts the variations of normal stresses in the tangential direction of the opening profile $\sigma_{\mathrm{nt}}$ monitored by the test and numerical simulation at the same locations in the specimen. Generally, the test and simulation results had the same variation tendencies, especially in the deep surrounding rock, such as $1.5 a$ from the opening profile. However, their vertical displacements of fracture were different. Table 3 and Figure 15 summarise the corresponding vertical displacements when the surrounding rock was fractured at locations $0 a, 0.5 a$, and $1.5 a$ from the opening profile, which are denoted by $d_{\mathrm{v} 0 a}, d_{\mathrm{v} 0.5 a}$, and $d_{\mathrm{v} 1.5 a}$, respectively. In Figure 15 , the dotted lines stood for the unfractured values. To investigate the differences between the numerical and experimental results, the difference values of the experimental and numerical $d_{\mathrm{v} 0 a}$ and $d_{\mathrm{v} 0.5 a}$ are denoted as $\Delta d_{\mathrm{v} 0 a}$ and $\Delta d_{\mathrm{v} 0.5 a}\left(\Delta d_{\mathrm{v} 0 a}=\right.$ experimental $d_{\mathrm{v} 0 a}-$ numerical $d_{\mathrm{v} 0 a} ; \Delta d_{\mathrm{v} 0.5 a}=$ experimental $d_{\mathrm{v} 0.5 a}-$ numerical $\left.d_{\mathrm{v} 0.5 a}\right)$, respectively. It can be seen from Table 3 and Figure 15 that, in both crown and floor, the numerical model (intact rock) $d_{\mathrm{v}}$ was much smaller than the test value. In the floor, $\Delta d_{\mathrm{v} 0 a}$ was approximately equal to $\Delta d_{\mathrm{v} 0.5 a}$, while it was different at the crown. Because the numerical model was continuum without cracks, this finding indicated that the original natural cracks in the surrounding rock (experimental specimen) can dissipate the strain energy 


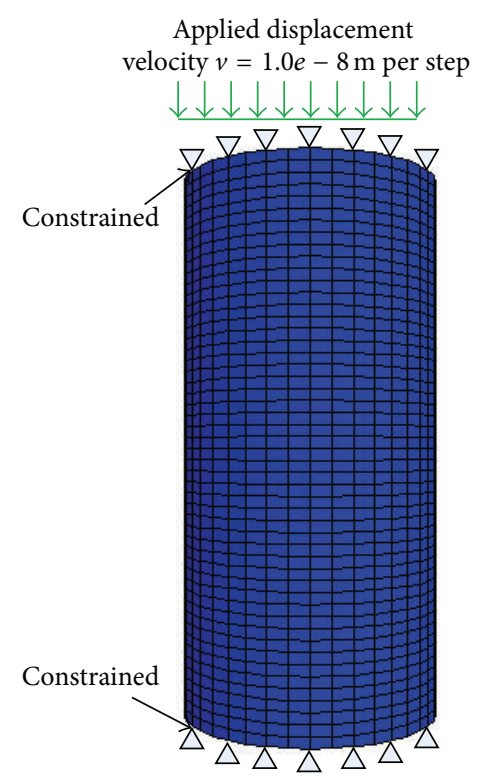

(a)

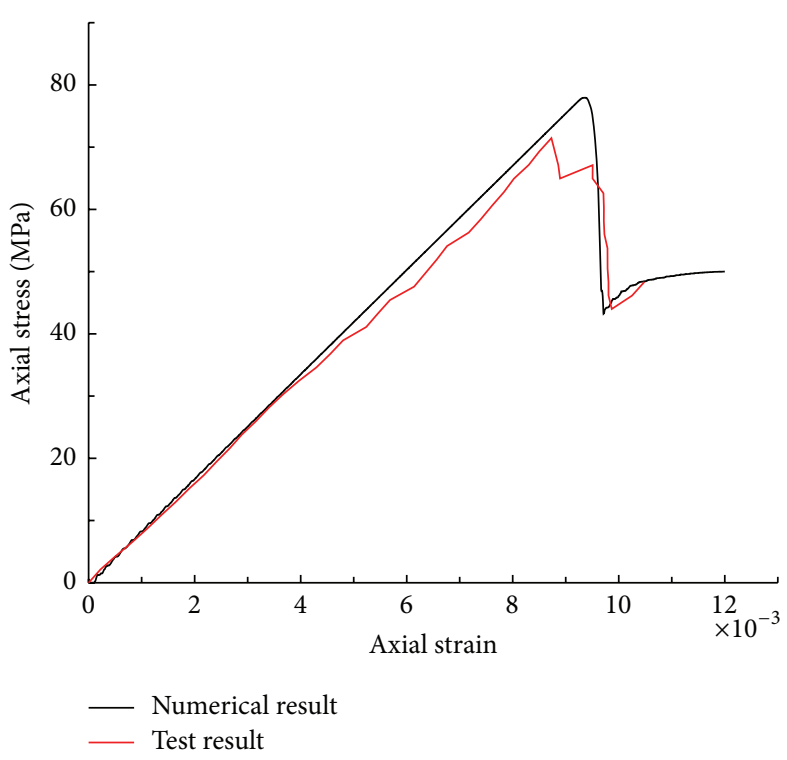

(b)

FIGURE 10: Comparison of the experimental and numerical results under uniaxial compression: (a) numerical model; (b) stress-strain curves.

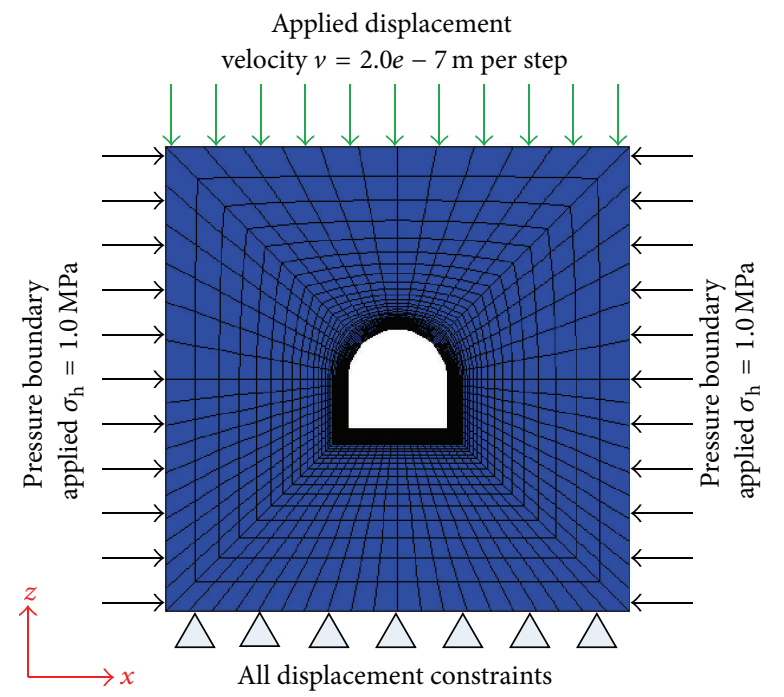

FIGURE 11: Grid and boundary conditions of the biaxial numerical model.

and then postponed fracture in the initial fracture stage. However, once the cracks were initiated, they propagated to fracture faster than those in the intact specimen (numerical model), especially at the crown.

Based on this comparison using the same geometrical dimensions and equivalent mechanical parameters, the numerical model of the perfectly intact specimen had a larger compression strength than those of naturally cracked specimen. However, under compression pressure, the cracks closed gradually and dissipated strain energy. They generated a much larger compression pressure at the initial fracture in the cracked surrounding rock. This is also why hysteretic fractures and weak rock bursts occurred often during the excavation of the Niba mountain tunnel.

\section{Conclusion}

In this study, uniaxial and biaxial compression tests were conducted on the naturally cracked rhyolite. The fracture modes and stress state were studied. The results of numerical simulation which was treated as intact rock were then compared with those of laboratory tests. According to the laboratory test and numerical simulation results, the following conclusions were drawn:

(1) The initiation stress of rhyolite was $43 \%$ of the uniaxial compressive strength. The AE monitoring and ultimate failure of uniaxial compression test showed that there were numbers of original cracks in the natural 


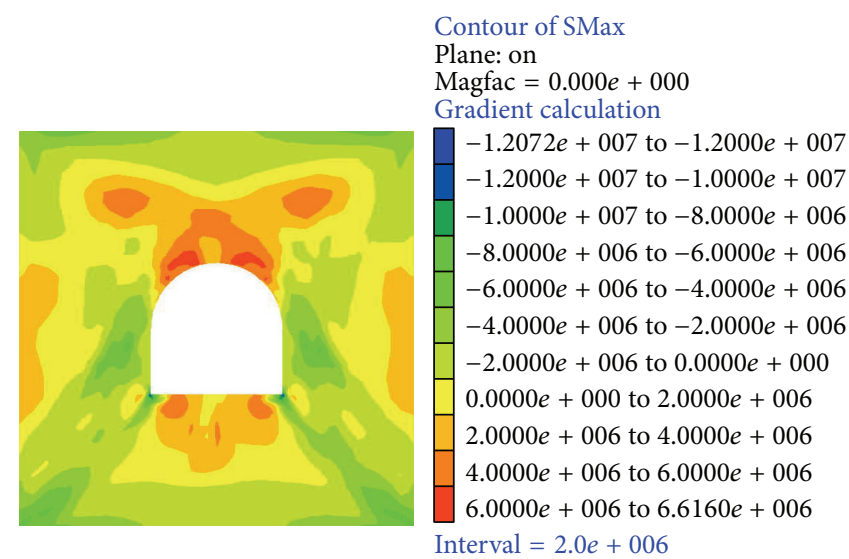

(a)

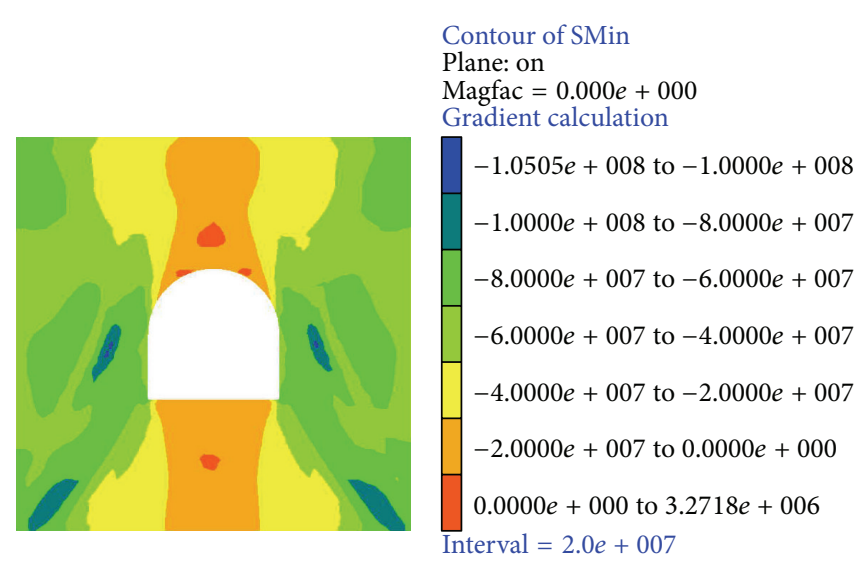

(b)

FIGURE 12: Numerical simulation results: (a) principal tensile stress, (b) principal compressive stress.

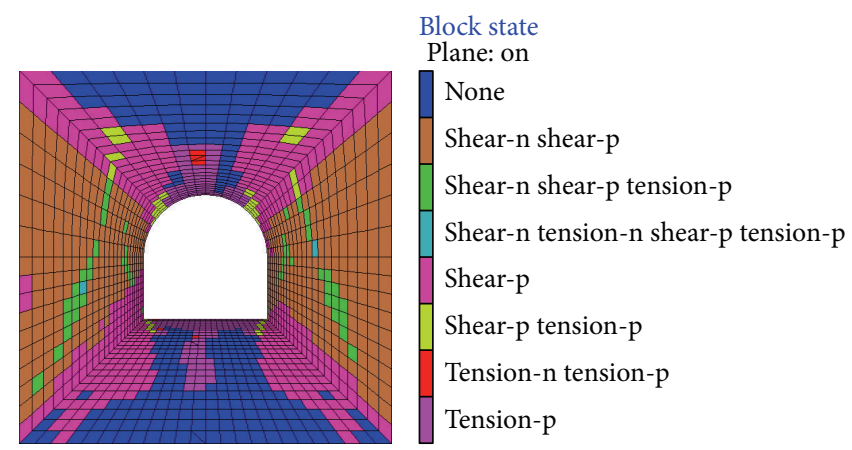

Figure 13: Plastic region of numerical result.

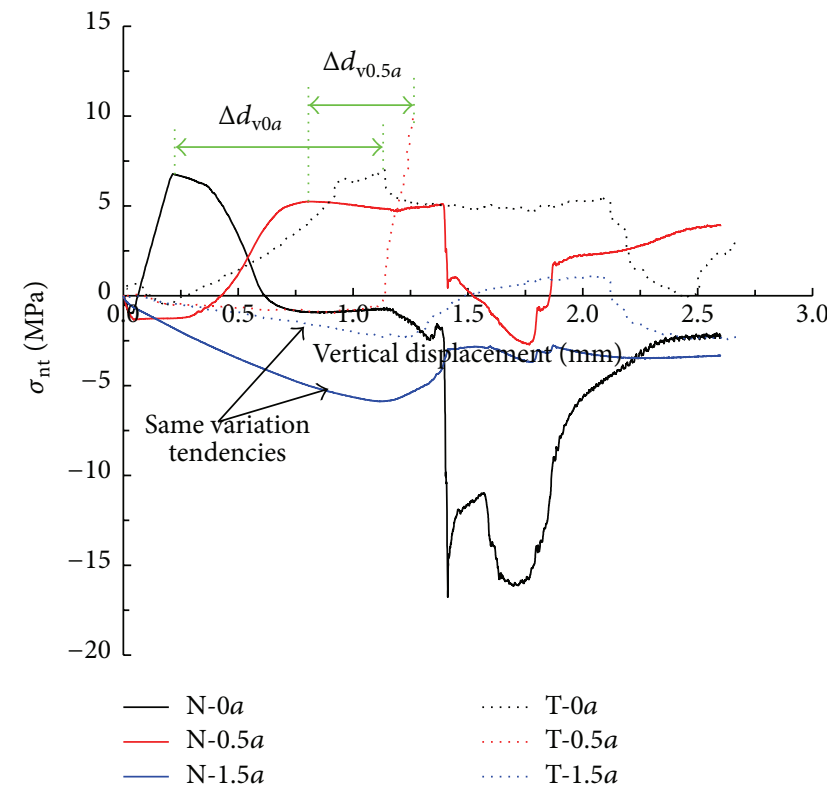

(a)

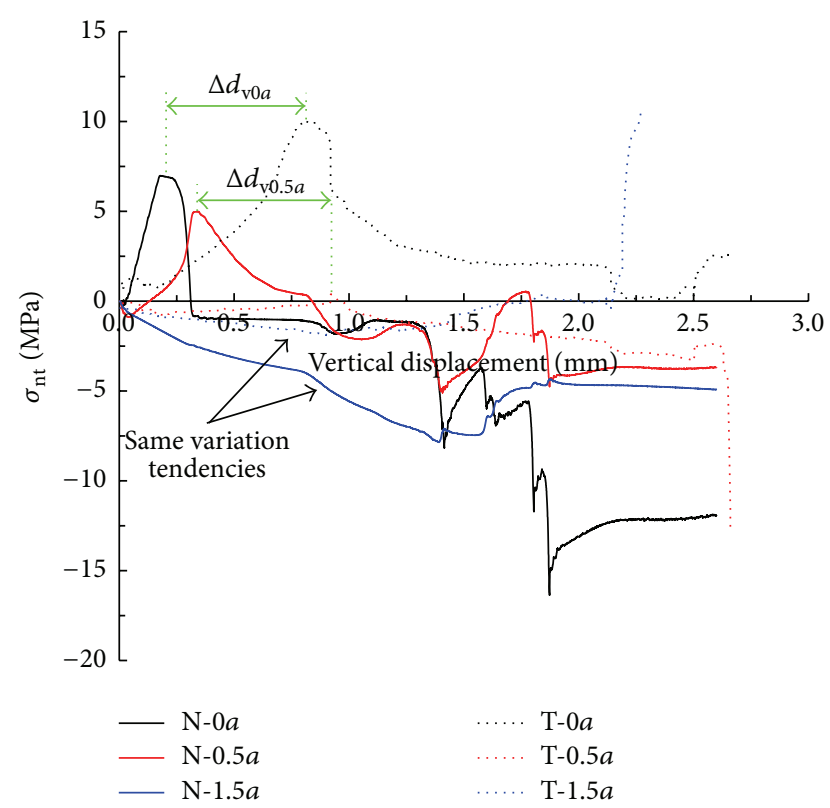

(b)

FIGURE 14: Normal stresses in the tangential direction of the opening profile: (a) the crown, (b) the floor. 


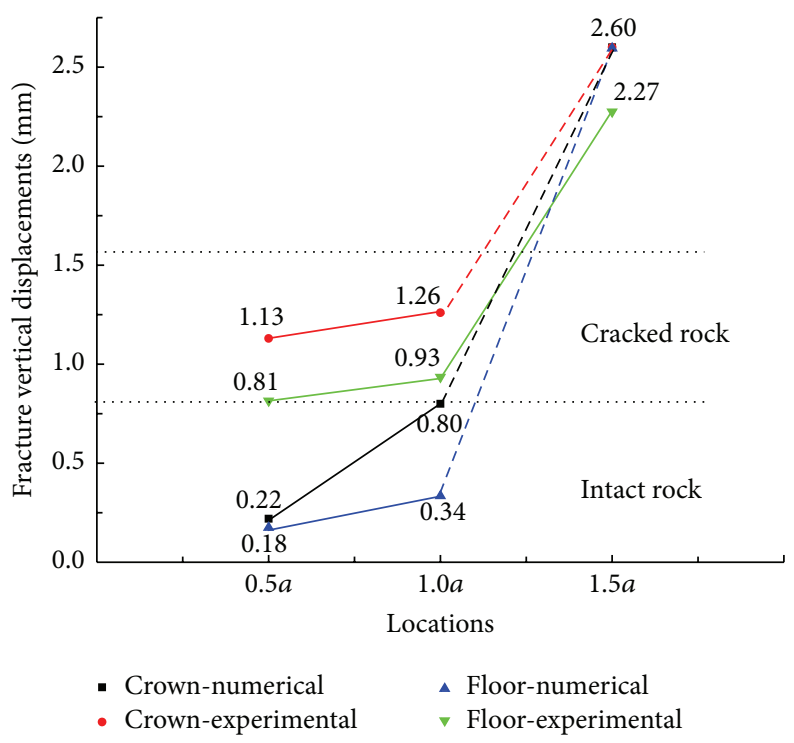

FIgURE 15: Comparison of numerical and experimental results.

rhyolite, which means that the rhyolite was naturally cracked and brittle.

(2) Regarding the analysis of the normal stresses in the tangential direction of the opening profile distributed around the inverted U-shaped opening, the floor rock was tensile fractured prior to the crown, and the "V-shaped" compression-shear fractured region is formed at the sidewall near the arch springing point. As the initiation, propagation, and coalescence of cracks, strain energy accumulated during the loading was released.

(3) Numerical model with intact rock had the same variations of surrounding rock stresses with laboratory test results. Compared to the perfectly intact rock numerical model, the crack initiation vertical displacement of laboratory test was larger, but the cracks propagate to deep surrounding rock faster. Meanwhile, the ultimate strength of the cracked biaxial specimen is lower, which means that the original cracks decreased the strength but postpone the initiation cracking of the surrounding rock. This behaviour of cracked surrounding rock had something to do with the strain energy releasing of original cracks. This process reveals the mechanism of hysteretic fractures of cracks surrounding the Niba mountain tunnel.

Moreover, this study also has some limitations. Although the application of the results presented in this study to practical projects is difficult, these results are significative to reveal the mechanism of hysteretic fractures in naturally cracked surrounding rock during the excavation of Niba mountain tunnel. It is also the basis for the systemic study of hysteretic fractures.

\section{Conflict of Interests}

The authors declare that there is no conflict of interests regarding the publication of this paper.

\section{Acknowledgments}

This research was supported by the National Natural Science Foundation of China (no. 41272321) and the Doctorial Innovation Foundation of Southwest Jiaotong University. The authors wish to acknowledge Mr. Xiong Hun for his help during laboratory tests.

\section{References}

[1] L. N. Y. Wong and H. H. Einstein, "Crack coalescence in molded gypsum and carrara marble: part 1. macroscopic observations and interpretation," Rock Mechanics and Rock Engineering, vol. 42, no. 3, pp. 475-511, 2009.

[2] R. H. C. Wong and K. T. Chau, "Crack coalescence in a rock-like material containing two cracks," International Journal of Rock Mechanics and Mining Sciences, vol. 35, no. 2, pp. 147-164, 1998.

[3] H. Lee and S. Jeon, "An experimental and numerical study of fracture coalescence in pre-cracked specimens under uniaxial compression," International Journal of Solids and Structures, vol. 48, no. 6, pp. 979-999, 2011.

[4] L. Jia, M. Chen, W. Zhang et al., "Experimental study and numerical modeling of brittle fracture of carbonate rock under uniaxial compression," Mechanics Research Communications, vol. 50, pp. 58-62, 2013.

[5] E. Eberhardt, D. Stead, B. Stimpson, and R. S. Read, "Identifying crack initiation and propagation thresholds in brittle rock," Canadian Geotechnical Journal, vol. 35, no. 2, pp. 222-233, 1998.

[6] R. T. Ewy and N. G. W. Cook, "Deformation and fracture around cylindrical openings in rock-II. Initiation, growth and interaction of fractures," International Journal of Rock 
Mechanics and Mining Sciences \& Geomechanics Abstracts, vol. 27, no. 5, pp. 409-427, 1990.

[7] A. Fakhimi, F. Carvalho, T. Ishida, and J. F. Labuz, "Simulation of failure around a circular opening in rock," International Journal of Rock Mechanics and Mining Sciences, vol. 39, no. 4, pp. 507$515,2002$.

[8] T.-T. Wang and T.-H. Huang, "Numerical simulation on anisotropic squeezing phenomenon of New Guanyin Tunnel," Journal of GeoEngineering, vol. 6, no. 3, pp. 125-133, 2011.

[9] T.-T. Wang and T.-H. Huang, "Anisotropic deformation of a circular tunnel excavated in a rock mass containing sets of ubiquitous joints: theory analysis and numerical modeling," Rock Mechanics and Rock Engineering, vol. 47, no. 2, pp. 643657, 2014.

[10] X. P. Zhou, F. H. Wang, Q. H. Qian, and B. H. Zhang, "Zonal fracturing mechanism in deep crack-weakened rock masses," Theoretical and Applied Fracture Mechanics, vol. 50, no. 1, pp. 57-65, 2008.

[11] X. P. Zhou, E. M. Xia, H. Q. Yang, and Q. H. Qian, “Different crack sizes analyzed for surrounding rock mass around underground caverns in Jinping I hydropower station," Theoretical and Applied Fracture Mechanics, vol. 57, no. 1, pp. 19-30, 2012.

[12] M. Sagong, D. Park, J. Yoo, and J. S. Lee, "Experimental and numerical analyses of an opening in a jointed rock mass under biaxial compression," International Journal of Rock Mechanics and Mining Sciences, vol. 48, no. 7, pp. 1055-1067, 2011.

[13] C. Zhang, Z. C. Wang, and Q. Wang, "Deformation and failure characteristics of the rock masses around deep underground caverns," Mathematical Problems in Engineering, vol. 2015, Article ID 230126, 13 pages, 2015.

[14] M. Souley, F. Homand, and A. Thoraval, "The effect of joint constitutive laws on the modelling of an underground excavation and comparison with in situ measurements," International Journal of Rock Mechanics and Mining Sciences, vol. 34, no. 1, pp. 97115, 1997.

[15] Y. H. Hao and R. Azzam, "The plastic zones and displacements around underground openings in rock masses containing a fault," Tunnelling and Underground Space Technology, vol. 20, no. 1, pp. 49-61, 2005.

[16] Y. Jiang, B. Li, and Y. Yamashita, "Simulation of cracking near a large underground cavern in a discontinuous rock mass using the expanded distinct element method," International Journal of Rock Mechanics and Mining Sciences, vol. 46, no. 1, pp. 97-106, 2009.

[17] W. C. Zhu, J. Liu, C. A. Tang, X. D. Zhao, and B. H. Brady, "Simulation of progressive fracturing processes around underground excavations under biaxial compression," Tunnelling and Underground Space Technology, vol. 20, no. 3, pp. 231-247, 2005.

[18] P. Jia and C. A. Tang, "Numerical study on failure mechanism of tunnel in jointed rock mass," Tunnelling and Underground Space Technology, vol. 23, no. 5, pp. 500-507, 2008.

[19] T.-T. Wang and T.-H. Huang, "A constitutive model for the deformation of a rock mass containing sets of ubiquitous joints," International Journal of Rock Mechanics and Mining Sciences, vol. 46, no. 3, pp. 521-530, 2009.

[20] R. G. Deng, X. M. Fu, J. Shao, and L. Deng, Study of the Rockmass Engineering Problems in Niba Mountain Deep and Long Tunnel, Southwest Jiaotong University Press, Chendu, China, 2010 (Chinese).

[21] S. C. Li, X. D. Feng, and S. C. Li, "Numerical model for the zonal disintegration of the rock mass around deep underground workings," Theoretical and Applied Fracture Mechanics, vol. 6667, pp. 65-73, 2013.

[22] M. R. Ayatollahi, M. R. M. Aliha, and H. Saghafi, "An improved semi-circular bend specimen for investigating mixed mode brittle fracture," Engineering Fracture Mechanics, vol. 78, no. 1, pp. 110-123, 2011.

[23] Z. B. Zhong, R. G. Deng, J. Li, and X. M. Fu, "Experimental study of triaxial mechanical properties of naturally fissured rhyolie," Chinese Journal of Rock Mechanics and Engineering, vol. 33, no. 6, pp. 1233-1240, 2014 (Chinese).

[24] G. Barla and M. Barla, "Continuum and discontinuum modelling in tunnel engineering," Gradevinar, vol. 52, no. 10, pp. 567-576, 2000.

[25] Y. Li, D. Zhang, Q. Fang, Q. Yu, and L. Xia, "A physical and numerical investigation of the failure mechanism of weak rocks surrounding tunnels," Computers and Geotechnics, vol. 61, pp. 292-307, 2014.

[26] R. G. Deng, Z. B. Zhong, X. M. Fu, W. M. Xiao, and J. Yin, "Experimental study on deformation and strength properties of microfissured rock," in Rock Characterisation, Modelling and Engineering Design Methods, X.-T. Feng, J. A. Hudson, and F. Tan, Eds., pp. 231-234, Taylor \& Francis Group, London, UK, 2013.

[27] Itasca, FLAC3D. Fast Lagrangian Analysis of Continua in 3Dimensions. Version 4.0, Manual, Itasca, Minneapolis, Minn, USA, 2009. 


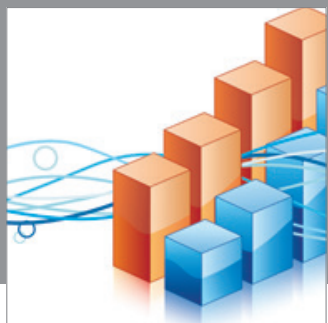

Advances in

Operations Research

mansans

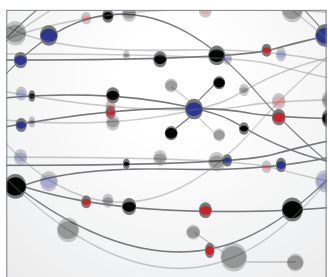

The Scientific World Journal
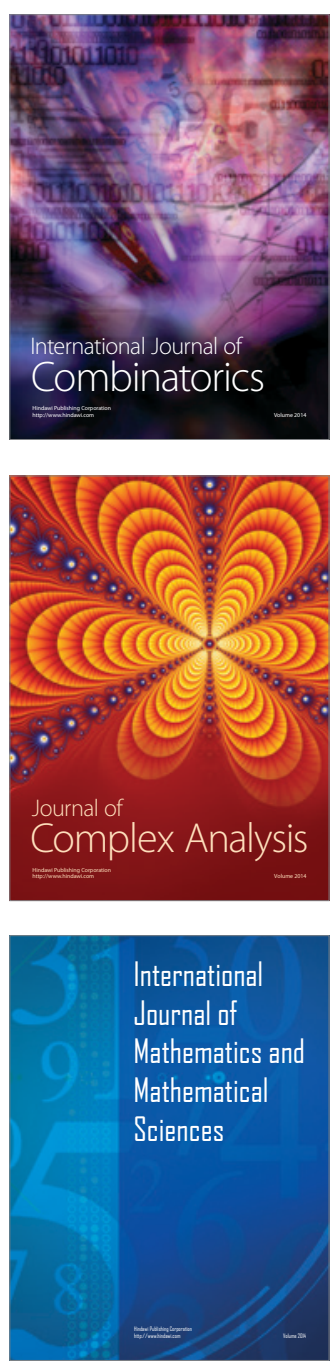
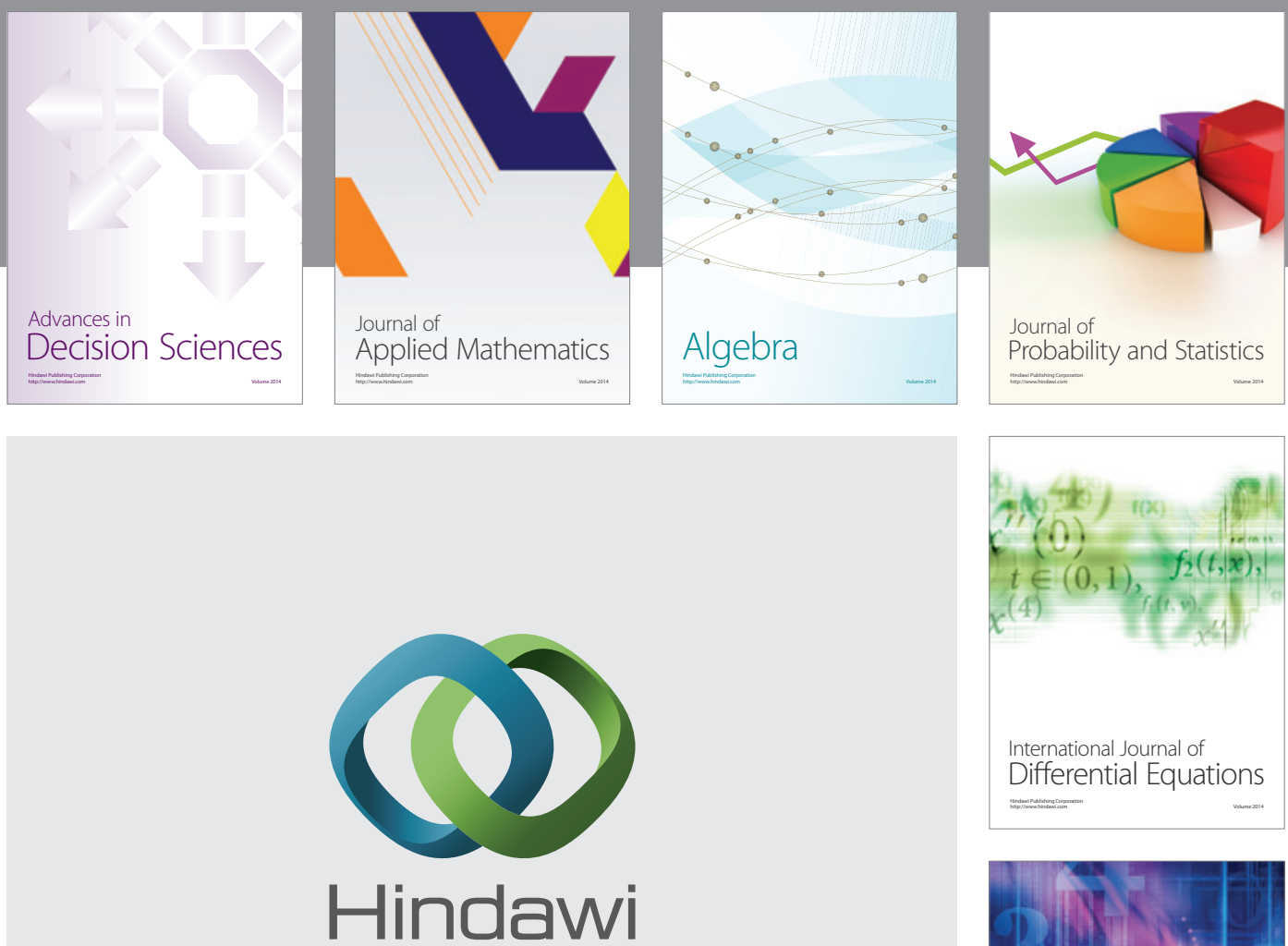

Submit your manuscripts at http://www.hindawi.com
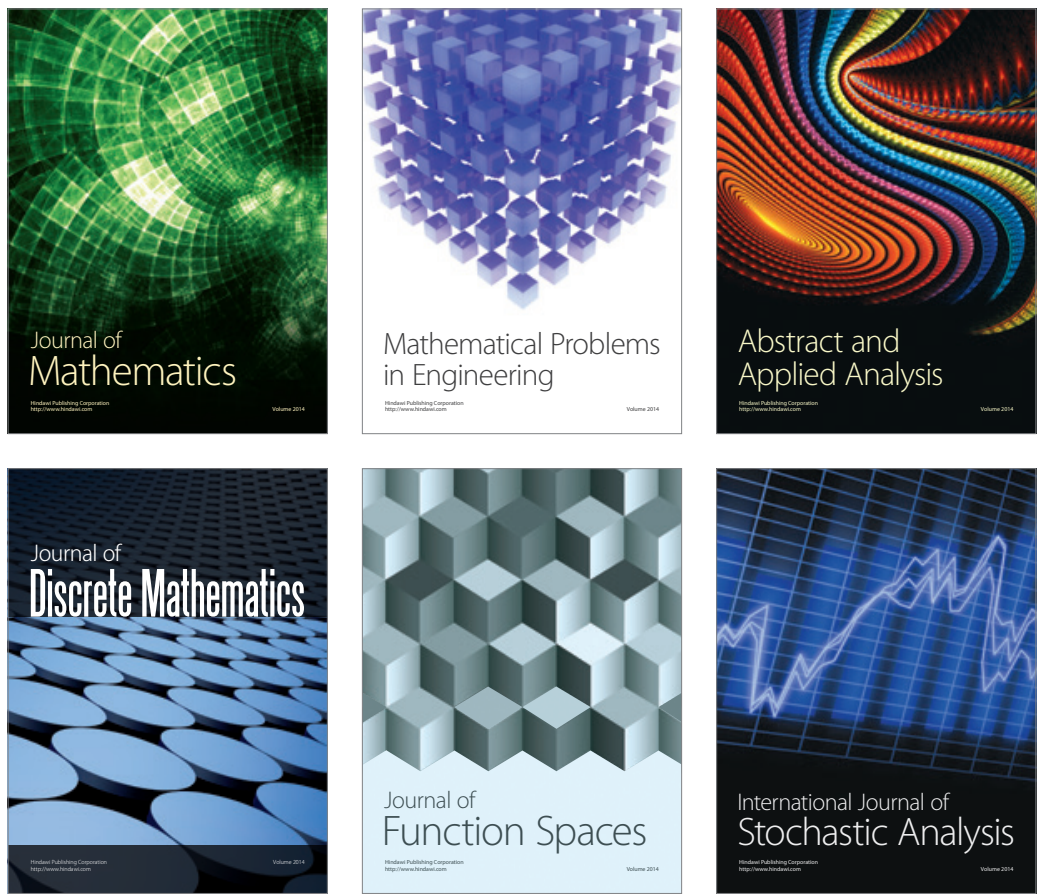

Journal of

Function Spaces

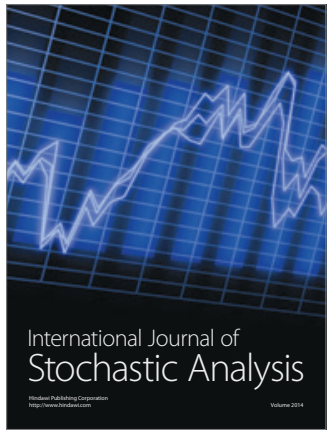

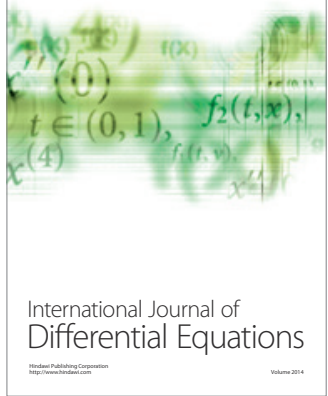
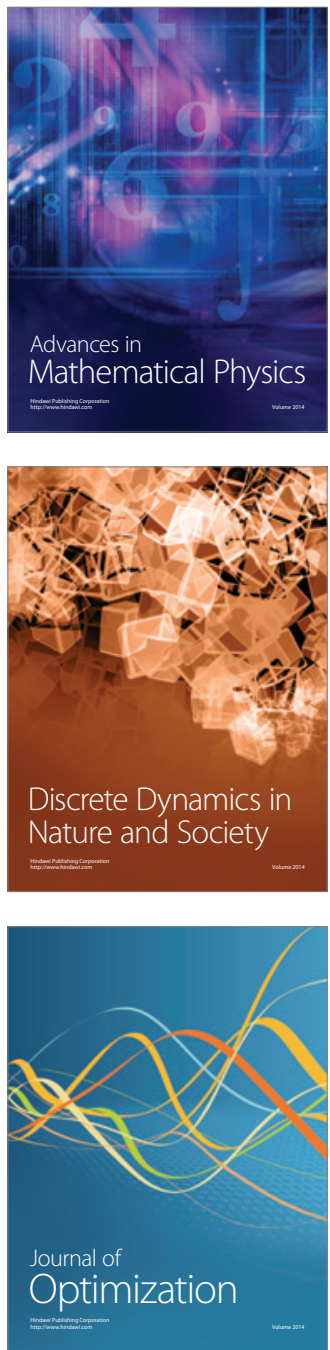